\title{
Performing Leadership: Use of Performative Inquiry in Teaching Organizational Theories
}

\author{
Dr. Michelle Nilson, \\ Dr. Lynn Fels \\ Dr. Bryan Gopaul
}

\begin{abstract}
This research explores the various ways in which performative inquiry was implemented in a graduate organizational theories course within an educational leadership cohort at a mediumsized urban Canadian research university. Drawing on Fink's framework for significant learning experiences, the researchers used performative inquiry to enact the "Practice" and "Reflection" domains of his pedagogical model. The data show that as the course unfolded, the class experienced a shift from instructor-centered transmission of information to a curriculum coconstructed by students and instructors. We conclude with ways in which educational leadership professors can incorporate performative inquiry as a teaching strategy to enhance the learning process for aspiring educational leaders.
\end{abstract}

\section{Introduction}

Participants sit back to back, eyes closed, classroom lights dimmed. They have been cast in the roles of different groups of stakeholders - administrators, faculty, students, parents, community members, and donors. They are ready to create a collaborative soundscape in response to an accreditation process proposed by a consultant.

"Begin," whispers the instructor.

Voices fill the room.

"We need this accreditation because we've got to figure out what is best to do."

"We've got to make the most of limited resources."

"Will this accreditation process take time from student learning?"

"How will my students benefit?"

"Will it count against me?"

"Will these accreditation results show up on my transcript?"

"What benefit is all this paperwork and accreditation for our community?

"How many of my tax dollars are going into this?"

"Is this going to effect our teaching evaluations?"

"How relevant is this to the curriculum?"

Listening to each other, the participants wonder: How will all these conflicting concerns be negotiated? Who will step forward in leadership to resolve these multiple perspectives? What is the right response? 
What happens when students in a leadership educational program are invited into performative spaces of creative interaction and inquiry, collaborative problem solving, and critical reflection? Since the 1990s, the field of leadership studies has transitioned from using trait theories of leadership to implementing a social constructionist paradigm (Fairhurst \& Grant, 2010). This shift has motivated leadership education programs to move away from leadership identification and individual human capital development in favor of a more systemic approach that focuses on developing social capital, fostering organizational contexts that support leadership development, and advancing interrelationships (Day, 2000; Komives, Longerbeam, Owen, Mainella, \& Osteen, 2006). The difference between leader development and leadership development is that "the primary emphasis in leadership development is on building and using interpersonal competence" (Day, 2000, p. 585).

In this paper, we share the results of the use of performative inquiry as a vehicle for engaging students in an organizational theories and analyses course in an educational leadership program. Performative inquiry recognizes the arts as an action site of research and learning; it is a pedagogical research strategy that incorporates arts, inquiry, and reflection to evoke and make meaning of emergent issues or situations encountered within performative spaces of encounter (Fels, 1998; 2010; 2011). Here, we outline the pedagogical activities that were part of the performative inquiry process as well as the students' reactions to these activities and their reflections on their own development during the semester.

\section{Literature}

While changes in views towards leadership have influenced the way that leadership is taught in non-formal and informal contexts, they have had a limited impact on pedagogy in formal contexts such as university classrooms. For example, the Council for the Advancement of Standards in Higher Education (CAS) noted three main ways in which postsecondary institutions provide educational leadership content: leadership training, leadership education, and development activities (2009). Student leadership training includes professional development for individuals associated with auxiliary functions such as student government and residence staffing. Student leadership education typically includes formal instruction associated with courses and includes theories, methods, and practices associated with leadership. Finally, development activities consist of sustained individual leadership development programs such as peer mentoring.

Drago-Severson, Ashgar, Blum-DeStefano, and Welch (2011) note that most university leadership preparation in $\mathrm{K}-12$ educational leadership programs "focuses on management skills (e.g., planning and financing), which are necessary but insufficient to help aspiring leaders meet anticipated leadership demands" (p. 84). Approaches to leadership education typically become evident in the explicit curriculum (Komives et al., 2006), through case studies (Grint, 2005), or in extracurricular activities, as with leadership positions in athletics (Grandzol, Perlis, \& Draina, 2010). Drago-Severson et al. argue that rather than take a management approach to leadership education, "programs need to teach about relational learning, collaborative leadership, and reflective practice" (p. 84). While evidence also suggests that arts-based leadership programs have a significant positive impact on leadership effectiveness (Romanowska, Larsson, Eriksson, Wikström, Westerlund, \& Theorell, 2011), these findings have had a limited impact on pedagogy 
in university classrooms.

The bulk of the scholarship that specifically addresses the teaching of organizational theories takes the form of case studies, teacher (practitioner) inquiry, or advocacy for pedagogical approaches. For example, Taber (2007), drawing on Morgan's (2006) metaphors for organizations, suggests using writing activities to introduce organizational theory concepts. Snyder (2014), referring to the current organizational leadership texts, declares, "[L]et's burn them all" (p. 1), instead advocating a pedagogy that incorporates new evidence from learning and neuroscience. This study, too, takes an advocacy approach: we aim not to test the efficacy of newer pedagogical approaches in higher education but rather to promote their wider use so that their utility might be explored in a variety of contexts.

As a framework for understanding and developing leadership capacities in students, Komives et al. (2006) propose a leadership identity development (LID) theory and suggest corresponding activities. This theoretical framework provides a stage-based model for fostering a formative understanding of leadership identity (Komives et al., 2009) as developing from initial awareness to, ultimately, integration/synthesis (Komives et al., 2005). Related leadership studies outline the development of students by examining individual subgroups, such as LGBT student leaders (Renn, 2007), while others seek to understand the intersections of race, gender, and sexual orientation as they influence the leadership capacity of students (Dugan, Komives, \& Segar, 2009).

In response to the call for a more collaborative, relational, and reflective approach to teaching educational leadership, several scholars have incorporated dramaturgy into their pedagogy and theoretical frameworks. While often associated with sociology, dramaturgy can be used to explore leadership from a constructionist perspective that "challenges the privileging of a researcher-imposed view of leadership in favor of lay actors' constructions of the concept" (Fairhurst \& Grant, 2010, p. 172). While this definition serves to underscore the constructionist view, it also illustrates a tendency to use dramatic jargon (e.g., lay actors) to describe leadership relationships.

Dramaturgy also serves as a vehicle for exploring questions about whether leadership is performance or is used as performance (Peck, Freeman, Six, \& Dickinson, 2009). Drawing on both constructionist and constructivist theories, Peck and Dickinson (2010) developed a framework that analyzes the links between theory and performance on three primary dimensions: enactment, narrative, and audience. While the current research did not focus on teaching drama, the use of reflective inquiry in the development of practice - dramatic or otherwise - remained important.

In contrast to dramaturgy, performative inquiry exposes tensions between pedagogical ways of being and research approaches, in so doing requiring participants to actively engage in inquiry and reflection. What matters as participants engage in performative activities is their recognition of metaphorical, symbolic, and emergent learning and connections to lived experience both within and outside the classroom. Consequently, we view performative inquiry as both performance and inquiry, as each serves as a pedagogical vehicle and also offers deeper understanding; both the performative aspects and the reflective aspects of this approach to 
pedagogy are necessary and essential.

In the following section, we outline the framework of the course design, the performative inquiry activities developed, and students' reflections on performative inquiry as an approach to developing interpersonal and social emotional skills within an educational leadership program. We also share the implications for future research and practice.

\section{Methods}

This study is an interdisciplinary collaborative inquiry established by two faculty members of the Faculty of Education at a single university. One of us is an arts education scholar and the other is a postsecondary educational leadership scholar. As such, this research is at once a case study (wherein the case is a single occurrence of a course at a university) and a practitioner inquiry (wherein the practitioner is simultaneously the instructor and researcher, answering questions and tensions [Berry, 2007] arising from practice) (Shagoury \& Miller Power, 2012).

This research took place over the Spring 2012 semester and involved postsecondary practitioners in an organizational theories and analysis course at a midsized Canadianresearch university. Eleven of the 14 students consented to having their reflections and class artifacts used in the research. The data consisted of two primary sets of artifacts: a set of four reflections on each weekend of class discussion and activities, content readings, and student experiences; and a fifth and final course summary reflection. Additional, unsolicited data included emails received by the instructor following completion of the course.

At the beginning of the semester, the students were made aware that the faculty were engaged in their own inquiry, but due to lessons learned from previous experiences, we approached the students for ethical consent to use the artifacts only after the course was complete and the institution had approved the course marks.

Analysis. Because both of the primary researchers are part of the same faculty at the same institution, a third party was hired to perform a content analysis of the three forms of primary documents to find emergent themes and discontinuities. These artifacts were analyzed over the summer and fall months of 2012. Both deductive and inductive analyses were incorporated into this research.

The deductive analysis explored the different stages of the leadership identity framework articulated by Komives et al. (2005). The extent to which participants' narratives involved references to operationalizations of stages of leadership identity development was investigated. The six stages of leadership identity development suggested by Komives et al. (2005) include a) awareness, b) exploration/engagement, c) leader identified, d) leadership differentiated, e) generativity, and finally f) integration/synthesis. Stage one is awareness, in which students begin to recognize that there are leaders in the world and that these people are external to the self. The second stage, exploration/engagement, is a developmental period during which individuals are immersed in group experiences such as school and extracurricular activities. In the third stage, leader identified, the individual views leadership in a hierarchical manner and attributes it to a 
position rather than an individual. In the fourth stage, leadership differentiated, the student moves away from rigid hierarchies and into a view of leadership as able to exist at any level of an organization and within groups of individuals working together. In the fifth stage, generativity, the student helps develop the leadership of others and is passionately committed to a set of values or objectives. In the sixth stage, integration/synthesis, the individual embodies leadership without needing a title or position. In the current study, narratives that contained references to leadership initially were coded as LID. A second round of coding more thoroughly explored these excerpts by examining the specific stages of Komives's framework that they addressed.

The inductive analysis involved a two-cycle process of coding (Saldaña, 2009). First, descriptive coding was employed to explore the major topics found in participants' narratives. The second cycle of coding generated a more comprehensive understanding of the data. The more specific goal of the second cycle was to make sense of categorical, thematic, conceptual, and theoretical organizations of the data (Saldaña, 2009). The second cycle involved pattern coding (Miles \& Huberman, 1994; Saldaña, 2009), which enabled the grouping of codes into more comprehensive themes and notions. As indicated below, the results reveal participants' understanding of leadership concepts in the context of practices of performative inquiry. Each of the quotations below is a typical response rather than an outlier.

Context. The university at which this study took place is a midsized (30,000 students), publicly funded comprehensive research university located in Western Canada. The site of inquiry was Organizational Theories and Analyses, a course taught in the Spring 2012 semester by the educational leadership faculty member as part of a master's-level educational leadership degree program. This was the second course in the program. The instructor of the previous course primarily used small group work, micro lectures, and dialogical approaches to teaching; it is fair to say that students had no previous exposure to arts-based or performative inquiry in the program.

The educational leadership program at this institution is a premium-fee professional program, and classes are held on five Friday nights and Saturdays over the course of 15 weeks. The cohort consisted primarily of postsecondary instructors, department heads, advisors, and local college and university administrators.

Structure of the Course. Fink (2003) argues that the goal of improving teaching in higher education faces a bottleneck at course design; he suggests that active learning in postsecondary institutions occurs under a set of conditions in which information and ideas, hands-on experiences, and reflection are part of the course design. Inspired by Fink, we incorporated these three components into the course under study in a manner we will articulate in the following section. Interestingly, as will be apparent from our findings, these three components proved to be critical for student learning.

Information and ideas. The leadership educator chose to intertwine readings and discussions of organizational theories and practices with performative activities drawn from exercises including role-play, soundscapes, etc. (Fels \& Belliveau, 2008). The course focused on organizational frames (Bolman \& Deal, 2008), which invite students to understand that 
organizational and leadership practices can be understood by making observations simultaneously based in and informed by our own frames or paradigms. Whether or not the leadership is aware of the framework within which the organization is operating, providing frameworks for building common or shared understanding allows students to bring insight to their lived experiences in the workforce. Providing information about the different lenses or frameworks of organizational theory enabled students to identify and reflect on the operational frameworks that they and their own organizations and leaders incorporate into their daily work practice.

These frames were introduced in two ways, through readings of texts and through the use of probing questions that drew on both external resources and students' own experiences and understanding of their contexts and "systems" of education.

Hands-on embodied experience and learning through performative inquiry. In graduate-level educational leadership courses, students typically learn about theories but rarely have an opportunity to apply them or even to preview their implementation. Often, graduate students are asked to reflect on previous experiences, but these reflections rarely are engaged with a physical activity.

Embodied, metaphorical, and interactive, performative inquiry involves activities such as role-play, improvisation, tableau, and other dramatic or arts-based exercises, providing opportunities for participants to actively embody, reflect on, and make connections between their experiences, relationships, and workplace encounters (Fels \& Belliveau, 2008). Table 1 provides detailed descriptions of each activity that was conducted in the initial workshop and class. 
Table 1.

Description of Performative Activities

\begin{tabular}{ll}
\hline Activity Name & Description \\
Soundscape & $\begin{array}{l}\text { Participants use their voices and/or other sounds to create a mood or } \\
\text { atmosphere or to provide insight into a particular role, situation, or event. } \\
\text { This is akin to role-play with just the audio. }\end{array}$
\end{tabular}

Found poetry Participants construct a poem that summarizes or captures the essence of a source using only the words in the source materials.

Fortunately/ A person begins to tell a story and stops after the first sentence or two. The unfortunately next person says, "But fortunately ..." and describes a turn of events. The next person says, "But unfortunately ..." and describes yet another turn of events. The story can be absurd or realistic — or even both. This continues until everyone has had an opportunity to contribute to the story line.

Car and driver This is a two-person silent activity (e.g., no telling directions). Person A closes his or her eyes while Person B directs the movement of the two-person team (Person A and B) around the classroom. Person B tapping on Person A's right shoulder indicates to move right; tapping on Person A's left shoulder indicates to move left. Gently tapping on Person A's head indicates to move straight ahead. In order to tell Person A to stop, Person B removes all contact. The goal is to try to avoid colliding with anything or anyone.

Exquisite corpse ("and then....")

Complete the scene

Tableau

Supporting each other sitting down/standing up

Filling empty spaces
This can be either a written or an oral activity. The initiator writes the first half of a sentence. The next person completes the first sentence and writes the first half of the second sentence. If written, folding the paper over at the top covers the first half of the sentence.

Two people create a scene together; a person steps in to re-create the scene, and one of the original team members leaves; another person steps in to recreate the scene, and the second original team member steps away. This continues until all participants have had an opportunity to be part of creating or re-creating a scene.

This exercise is akin to a living photograph. In the tableau activity, the participants create a frozen scene (using just their bodies and available classroom props) that conveys an idea from the text.

Two participants hold hands while they both sit down or stand from a sitting position. It is best to match partners according to approximate weight and size.

This exercise has stages in which members are added to groups. During stage one, each individual stands with his or her arms outstretched at a 90-degree angle in front of him or her. Individuals must move through the room without hitting each other. Stage two begins with two people with interlocked arms.

Note. Table adapted from Fels \& Belliveau (2008). 
Participants simultaneously draw on their lived experience (van Manen, 1997), prior knowledge, and imagination as they participate in performative play, and through reflection, they come to recognize emergent learning. Performative inquiry embodies the requirements of selfstudy: reflection, collaboration, openness, and situated inquiry (Samaras \& Freese, 2006). Incorporating David Appelbaum's (1995) concept of the stop, a moment of risk, a moment of opportunity, performative inquiry invites participants to attend to critical emergent moments that "tug on the sleeve," which occur during their participation in the activity, and to reflect upon why those moments matter. A stop moment may be related to words spoken, actions taken, encounters, feelings, questions, and/or responses. Upon individual or collaborative reflection, in writing and/or through dialogue, the learning embodied within the activity is revealed and illuminated (Fels, 2012).

The students had a half-day workshop with the arts-based coinvestigator and an expert in arts for social change. This workshop consisted of an introductory period during which each student stated her or his name and explained why he or she was there. Then the class embarked on a series of performative activities over a period of approximately three hours. Each activity was debriefed with the questions "What did you notice?" and "How does it connect to your experiences at your workplace?" Engaging in hands-on embodied performative activities encouraged the students to develop metaphorical and embodied ways of knowing.

A list of class activities and a brief description of each can be found in Table 1. The performative activities listed were inspired by Fels and Belliveau's Exploring Curriculum: Performative Inquiry, Role Drama, and Learning (2008). The activities are presented here with descriptions of how they were used in the current research - an organizational theories course within a postsecondary educational leadership cohort - but they can be adapted to suit other contexts. Not all activities were engaged in to the same level. Some were introduced in the first weekend and never returned to in the remaining classes, while other activities were engaged in on two or more occasions. The instructor and students codetermined which specific performative approaches would be used in class and the frequency with which they would be used. Finally, all of these activities were followed by a reflection period so that students could draw their own connections between the activity and the content of the course or their own professional experiences.

Reflection. The students engaged in reflection in three ways: quick writes, learning reflections, and a summary reflection. The quick writes used prompts provided just after the weekly debriefing to help focus the students on the content they had read and to ground their thinking for later activities. Some examples of quick writes are:

1. Select a quote, passage, sentence, or idea from Chapter 8 that resonates or causes tensions in your thinking. What is it about this idea that you like or that challenges your thinking? How do you think this will be useful or informative for your evaluation or capstone project?

2. As you think back on your evaluation proposal, what do you think is the most important (to you) thing you hope to learn about? How does this relate to your work and what you tend to value most about it? 
The learning reflections were conducted after each weekend of class; these prompted students to reflect on (a) the discussions and (b) the activities that they engaged in during class. At the end of the semester, students were also asked to write brief (2-5 page) summary reflections; they were invited to draw on their weekly reflections and quick writes as sources of evidence of their learning and growth over the term. Several students commented throughout the term that reflective writing taught them a lot about their thinking and that they will continue to use it in their practice and studies.

\section{Results}

Our initial findings support the idea that using performative inquiry in educational leadership cohorts shows promise as a method of engaging students in meaningful ways. The effectiveness of performative inquiry as a learning strategy within educational leadership courses was evident, as students made connections between their lived experience in the workforce, the theoretical concepts explored, and the experiences they shared as they completed the individual performative activities.

For example, in the "complete the scene" activity, in which one student would form a shape with his or her body and another would join him or her to turn the shape into a scene, students were able to see that their original assumptions were transformed from possible truths to absurdities. This activity was particularly useful in helping students explore their assumptions about what they observed. Similarly, "fortunately/unfortunately" encouraged students not only to reflect on possible realities based on a given story line but also to consider alternative realities suggested by changes to that story line. Listening, thinking on the spot, and changing a story line to make it coherent reminded students of real-life situations in which plans had to be altered or new actions taken because expectations failed to play out. In each instance, the instructor debriefed with the students about the activity to discuss why their experiences might be relevant to the content they were exploring and how upon reflection the activity and their experiences could connect to their workplaces.

In another activity, students were asked to clasp each other's wrists in pairs and lean backwards, taking each other's weight, then sit down and stand up again. In debriefing, students talked about the need for trust in one another and a willingness to "release control" and share the burden in order to make the exercise successful. "How does this activity relate to your own actions at work?" the workshop coordinator asked them afterwards. In such activities, from roleplay to soundscapes, tableau to simple drama games, participants made connections between class activities, course content, and their own workplace environments, the activities and subsequent discussions reinforcing lessons and bringing emergent learning to the surface.

Of particular value and indicative of the effectiveness of learning through performative inquiry was the soundscape students created to represent the points of view of different stakeholders - parents, teachers, administration, students - in an evaluation project. By vocalizing and hearing multiple perspectives through the soundscape, participants could better comprehend the complexity of the issue under evaluation and understand how resolution was 
achieved not by "getting it right" but rather through negotiation and acknowledgement of the nuances of conducting evaluation.

What Mattered. Initially, introducing performative inquiry as a learning strategy generated resistance from some students, who viewed the performative activities with skepticism, wondering whether or not they would be valuable to learning. "I enjoyed Saturday because it was a different experience with this group of people but I'm having trouble understanding the full value of the exercises. . . I'm just having trouble understanding how it relates to Organizational Theory" (Emma, Weekend 1 Learning Reflection). Alex (Weekend 1 Learning Reflection) observed, "I remain skeptical (another Greek term) of the benefits of performance inquiry for myself or in my workplace but remain open minded enough to see its value in other applications." Similarly, another student noted:

When we began the tableau exercise my first thought was "Yikes! This was the least useful part of the first weekend and is the point in which I shut down - way to[o] loosygoosy for me. ... [O]nce we were into the class presentation and discussion I realized that the exercise was very beneficial and I was absorbing the class content. (Diana, Weekend 1 Learning Reflection)

Others expressed concern related to issues of trust and control in that they felt vulnerable having to rely on others, which in turn led to interesting conversations about leadership in the workplace. For example, Magda (Weekend 1 Learning Reflection) noted "[W] on someone else to make the decisions such as the car and driver activity, I had to fight the desire to ignore the directions and use my own judgment to navigate around the room." Another student noted that the activities:

$[\mathrm{H}]$ elped me to realized [sic] the limitation of the inter dependency among the co-workers in a workplace, especially during the activity of "holding arms and putting weight outwards" this activity helped me to realize that there is a optimal balance between the number of participants. (Charles, Week 1 Learning Reflection)

Changing the script in the conventional university classroom from transmission of information to collaborative performative exploration, which requires creative hands-on and collaborative embodied experience, can be initially unsettling for students and instructors. Participants have to undo what they know or expect in order to learn anew. However, over time the majority of students recognized the value of performative inquiry as a pedagogical strategy for exploring organizational theory and leadership. Most students' perception of the activities was that their value lay in their strong metaphorical connections to the workplace. Students also noted that pairing performative inquiry with the introduction of conceptual ideas such as Bolman \& Deal's (2008) four-frame model of organizational theory enabled them to change their perceptions of their relationships to their workplaces and their concepts of leadership and to gain a deeper understanding of organizational theory. Both written and spoken reflections referred to the impact that engaging in performative inquiry had on students' understanding of the course content and their relationships with each other and at work. For example, a student observed: 
[W] hen we were asked to link arms with 4 other individuals and "fill empty space" as much as possible, I saw a connection to the political frame. I felt that groups began to get competitive in trying to fill empty space and this made me think of the fighting for scarce resources that often occurs in organizations. (Babette, Week 1 Learning Reflection)

Similarly, another noticed:

I find myself not only looking at the classes but also on how applicable the HR frame has been in my work this week. ... [I] find that the immediacy of the theory to practice makes for a more potent learning outcome. (Diana, Week 3 Learning Reflection)

Interestingly, Fink's key components - ideas and information, hands-on experience, and reflection - which had influenced the course design, resurfaced in the reflective writing as elements the students considered critical to their learning. Components emerged that informed us of which aspects of engaging in performative inquiry with students in educational leadership programs reinforce which learning goals. First, the metaphorical embodied understanding that arose through participation in performative activities and reflection brought forth new understanding that connected textbook theory, ideas, and information to lived experience in the workplace. Engaging in performative inquiry required group collaboration and problem solving, connective learning, and critical and creative thinking, all critical components of successful leadership. For example, "I liked the interactive sessions; it helps put our reading into practice" (Darrell, Weekend 2 Learning Reflection). Other students similarly reflected on these connections:

I thought it was interesting how our group almost spontaneously split into two for better management to illustrate the pros and cons of our frame, which in the end turned out well. I am often amazed by the creativity that can develop in such short periods of time. (Amber, Weekend 3 Learning Reflection)

I thought this was a great activity to demonstrate the human resources frame in action. In the workplace we often have limited time/resources, opened ended goals, many options for action, and many people involved in the decision making process. The issues we experienced during the morning show why it is important to have structure in the workplace. (Jacob, Weekend 3 Learning Reflection)

Second, numerous students indicated that reflection played a key role in their learning in relation to both the performative activities they used to explore theories and concepts offered by the course materials and their understanding of their relationships with their workplaces. Reflection is well recognized as a significant component of student learning (Boud, Keogh, \& Walker, 1985; Calderhead, 1992); engaging in reflection is particularly critical to learning through performative inquiry (Fels, 2015).

It wasn't until near the end of the second class and upon reflection of the weekend, that I saw the similarities to the subject area and the quick writes. For example, looking at my written thoughts on what makes a good organization and leader was very obviously illustrated when we did the leadership orientation questionnaire. (Amber, Weekend 2 Learning Reflection) 
Third, the information and ideas themselves play a critical role in student learning when introducing performative inquiry into a classroom setting. Engaging in performative activities within the context of leadership and organizational theory invited metaphorical, symbolic, and lived-experience connections with the material students were learning and its application to the workplace and their lives.

This week I found that the theories we've been learning have become more applicable in my daily professional life and that I am beginning to look at things through multiple frames. I am also finding it easier to analyze those I work with and look at the frames they work most comfortably in. (Diana, Weekend 4 Learning Reflection)

Prior to this course I always tried to avoid conflict. However Bolman \& Deal ( p. 207) [sic] helped clarify that conflict is healthy. As such, I know that I need to learn more about effective strategies and techniques to manage and better facilitate conflict for innovative and proper management processes. Something to add to my toolkit! (Grant, Weekend 5 Learning Reflection)

Reflection allowed students to relate discomfort at being led around a room with closed eyes by a partner to the challenges faced when leadership requests change without providing background information or a rationale. Performative activities undertaken within the context of theoretical frameworks and concepts enabled students to transfer these ideas to their lived experience. Performative inquiry does not exist in a vacuum but rather requires a context within which metaphorical and lived-experience connections may be recognized:

In terms of personal reflection I realized, through performative inquiry activities, that I thrive on structure and control and feel very nervous about embarking on activities where there is an element of the unknown and others are leading. (Babette, Weekend 5 Learning Reflection)

During the course, sufficient time was dedicated to using performative inquiry to deeply explore theoretical concepts, their applications, and their limitations in order for an embodied metaphorical understanding of the concepts to emerge. One student's final reflection beautifully articulates the change over time:

In week one I was outside of my comfort zone during the performative inquiry, as I quickly began to recognize my need to control situations. A few classes later I reflected after a group exercise that I seem to prefer to take the lead in groups and try to steer the direction. I had a "stop moment" in class and asked myself, why I feel I need to take the lead and why can I not take a step back and let others initiate. Do I consider myself to be a good leader or am I uncomfortable giving up control and letting others make decisions? ... I am now aware of the importance of taking a moment to look at the bigger picture, of recognizing who is involved and considering their agendas and motivations, as well as their personalities, strengths and weaknesses. (Wayne, Week 5 Final Learning Reflections) 
As noted earlier, relational learning, collaborative leadership, and reflective practice are necessary components of educational leadership programs. And yet, opportunities to experience or practice relational learning, collaborative leadership, or reflective practice are often limited in conventional programs. The incorporation of performative inquiry into our course provided students with opportunities to engage in all three components: relationships and interactions were explored through creative and critical engagements with roles; students were required to brainstorm, problem solve, and make decisions together as they worked out their scenes and activities; and students were actively engaged in their own meaning-making through the reflective writing that followed performative activities. Reinforcement by additional reflective writing incorporated throughout the course ensured that students developed an understanding of reflective practice as a valuable and meaningful enterprise in their learning within the classroom and their individual workplaces.

\section{Scholarly Significance}

This research offers valuable information to educators and administrators at the postsecondary level about leadership education across disciplinary boundaries. The study answers a call to incorporate more critical reflection, teamwork, communication, and engaged learning in leadership courses and is a promising way to foster leadership development and organizational understanding at the postsecondary level. It also points the way to a valuable integration of leadership development theory and arts-based research. While we are still in the early stages of this work, we are enthused by the responses of both the students and the instructor. While not initially part of our research objectives, our collaboration together as coresearchers is proving fruitful in terms of cross-disciplinary learning and professional development. Also important is the aforementioned value of providing an introductory workshop to equip students with the vocabulary and embodied experience of performative inquiry.

We also found that providing structured time at the beginning of each class for reflective writing enabled students to include more detailed descriptions of the activities and their own thoughts in the subsequent weekly reflections than they would have were they asked to do the reflective writing exclusively outside of class. Noticeably, several students took notes while engaged in the activities. The instructor was also engaged in reflective writing and modeling the reflective inquiry process, which several students mentioned as important to their own process of becoming comfortable with reflective writing in a group setting.

The original purpose of this research was to explore the potential of a pedagogy based in performative inquiry to foster deepened student engagement with ideas and information. Based on an examination of the final organizational case studies, we found that the students developed a deeper understanding of organizational frames and were better able to integrate multiple perspectives into their understanding of the cases. Importantly, that impact did not cease at the end of the term. For example, in the three terms following this research, students emailed the instructor to share that they were continuing to use the performative approaches to learning introduced in the course. Here is an excerpt from an email a participant wrote during the first semester following this research: 
[New instructor] has us doing small group presentations on articles for the policy class (not for marks). We have been through two rounds already and rather than just read summaries of the articles some groups are creating excellent interactive activities. There has been some case study type activities, some that have role playing, and one group even did a Jeopardy type game to check for learning. The most interesting part is we are spending more time planning these activities outside of class than we really should be (lots of other reading and assignment we should be working on). On the last group presentation my group started the email thread saying: "let's keep this one simple, it's not for marks." When I checked my email a week later (I was on vacation) there was at least three ideas using various forms of performative inquiry from my group members.

While these classroom activities we have been planning for our presentations have been consuming time in and outside of class they have been very helpful for actively engaging the policy course content with the group. I think we have learned much more than if each group had just presented the ideas from the articles like we were originally asked. It seems to me that the past experience in performative inquiry has intrinsically motivated us to create interactive presentations and created opportunities for active learning. (Jacob, July 8, 2012, personal communication)

Evidence of continued engagement with ways of approaching content influenced by performative inquiry was still present in subsequent semesters.

What is also notable is that engagement with this pedagogy has altered the ways in which the educational leadership instructor has taught since this research. Elements of performative inquiry and reflective inquiry have made their way into subsequent courses and into the program outcomes. For instance, this research and teaching experience motivated the educational leadership faculty member to develop a reflective portfolio as part of the culminating demonstration of knowledge for the degree program; a reflective portfolio is now an option for students completing this program.

In future research, we hope to explore the development of leadership identity through performative inquiry and reflective writing using the six-stage model of leadership identity development proposed by Komives et al. (2006) as both an analytical and a pedagogical framework. Through this work, we have also become more aware of literature that explores the relationships between leadership ability and embodiment. Another interesting extension of this research would be to explore the ways in which students conceive of and embody leadership and to track how that changes over a course or degree program. For example, Peck and Dickinson's leadership performance (2010) framework and Fels' (1998, 1999, 2010) notions of performative inquiry provide a foundation for evaluating performance and performativity similar to that of Sommerfeldt, Caine, and Molzahn's (2014) work with healthcare practitioners. In combination, these frameworks would provide a powerful set of tools for analyzing both the performance of leadership and the development of leadership identities. 


\section{References}

Appelbaum, D. (1995). The stop. Albany, NY: State University of New York Press.

Berry, A. (2007). Reconceptualizing teacher educator knowledge as tensions: Exploring the tension between valuing and reconstructing experience. Studying Teacher Education, $3(2), 117-134$.

Bolman, L. G. \& Deal, T. E. (2008). Reframing organizations: Artistry, choice, and leadership ( $4^{\text {th }}$ ed.). San Francisco, CA: Jossey-Bass.

Boud, D., Keogh, R., \& Walker, D. (Eds.). (1985). Reflection: Turning experience into learning. New York, NY: Routledge.

Calderhead, J. (1992). The role of reflection in learning to teach. In L. Valli (Ed.), Reflective teacher education: Cases and critiques. Albany, NY: State University of New York Press.

Council for the Advancement of Standards in Higher Education. (2015). CAS professional standards for higher education ( $9^{\text {th }}$ ed.). Washington, DC: Author.

Day, D. V. (2000). Leadership development review in context. Leadership Quarterly, 11(4), 581-613.

Drago-Severson, E., Ashgar, A., Blum-DeStefano, J. \& Welch, J. R. (2011). Conceptual changes in aspiring school leaders: Lessons from a university classroom. Journal of Research on Leadership Education, 6(4), 83-132.

Dugan, J. P., Komives, S. R., \& Segar, T. C. (2009). College student capacity for socially responsible leadership: Understanding norms and influences of race, gender, and sexual orientation. Journal of Student Affairs Research and Practice, 45(4), 927-952. doi:10.2202/1949-6605.2008

Fairhurst, G. T. \& Grant, D. (2010). The social construction of leadership: A sailing guide. Management Communication Quarterly, 24(2), 171-210.

Fels, L. (1998). In the wind, clothes dance on a line. jct: Journal of Curriculum Theorizing, 14(1), 27-36.

Fels, L. (2004). Complexity, teacher education and the restless jury: Pedagogical moments of performance. Complicity: An International Journal of Complexity and Education, 1(1), 73-98.

Fels, L. \& Belliveau, G. (2008). Exploring curriculum: Performative inquiry, role drama, and learning. Vancouver, BC, Canada: Pacific Educational Press. 
Fels, L. (2010). Coming into presence: The unfolding of a moment. Journal of Educational Controversy, 5(1). Bellingham, Washington: Western Washington University. Retrieved from http://www.wce.wwu.edu/Resources/CEP/eJournal/v005n001/a020.shtml

Fels, L. (2011). A dead man's sweater: Performative inquiry embodied and recognized. In S. Schonmann (Ed.), Key concepts in theatre drama education (pp. 339-343). Rotterdam, Netherlands: Sense Publishing.

Fels, L. (2012). Collecting data through performative inquiry: A tug on the sleeve. Youth Theatre, 26, 50-60.

Fels, L. (2015). E-Postcards: Reflection as a scholarly pedagogical act. In W. Linds \&E. Vettraino (Eds.), Hall of mirrors: Applied theatre as reflective pedagogical practice. Rotterdam, Netherlands: Sense Publishers.

Fink, L. D. (2003). Creating significant learning experiences: An integrated approach to designing college courses. Hoboken, NJ: Wiley and Sons.

Grandzol, C., Perlis, S., \& Draina, L. (2010). Leadership development of team captains. Journal of College Student Development, 51(4), 401-418.

Grint, K. (2005). Problems, problems, problems: The social construction of "leadership." Human Relations, 58(11), 1467-1494.

Komives, S. R., Owen, J. E., Longerbeam, S. D., Mainella, F. C., \& Osteen, L. (2005). Developing a leadership identity: A grounded theory. Journal of College Student Development, 46(6), 593-611.

Komives, S. R., Longerbeam, S. D., Owen, J. E., Mainella, F. C., \& Osteen, L. (2006). A leadership identity development model: Applications from a grounded theory. Journal of College Student Development, 47(4), 401-418.

Komives, S. R., Longerbeam, S. D., Mainella, F., Osteen, L., Owen, J. E., \& Wagner, W. (2009). Leadership identity development: Challenges in applying a developmental model. Journal of Leadership Education, 8(1), 11-47.

Miles, M. B. \& Huberman M. (1994). Qualitative data analysis: An expanded sourcebook. Thousand Oaks, CA: SAGEPublications.

Morgan, G. (2006). Images of organization. Thousand Oaks, CA: SAGE Publications.

Peck, E., Freeman, T., Six, P., \& Dickinson, H. (2009). Performing leadership: Towards a new research agenda in leadership studies? Leadership, 5(1), 25-40.

Peck, E. \& Dickinson, H. (2010). Pursuing legitimacy: Conceptualising and developing leaders' performances. Leadership \& Organization, 31(7), 630-642. 
Renn, K. A. (2007). Gay, bisexual, transgender, and queer identified college student leaders and activists. Journal of College Student Development, 48(3), 311-330.

Romanowska J., Larsson G., Eriksson M., Wikström B. M., Westerlund H., \& Theorell T. (2011). Health effects on leaders and co-workers of an art-based leadership development program. Psychotherapy and Psychosomatics, 80(2), 78-87.

Saldaña, J. (2009). The coding manual for qualitative researchers. Thousand Oaks, CA: SAGE Publications.

Samaras, A. \& Freese, A. (2006). Self study of teaching practices. New York, NY: Peter Lang.

Shagoury, R. \& Miller Power, B. (2012). Living the questions: A guide for teacher researchers. Portland, ME: Stenhouse Publishers.

Snyder, R. A. (2014). Let's burn them all: Reflections on the learning-inhibitory nature of introduction to management and introduction to organizational behavior textbooks. Journal of Management Education, 38(5), 733-758. doi:10.1177/1052562913502481

Sommerfeldt, S. C., Caine, V., \& Molzahn, A. (2014). Considering Performativity as Methodology and Phenomena. Forum Qualitative Sozialforschung / Forum: Qualitative Social Research, 15(2), Art. 11, Retrieved from http://nbn-resolving.de/urn:nbn:de:0114fqs1402112.

Taber, T. D. (2007). Using metaphors to teach organizational theory. Journal of Management Education, 31(4), 541-554. doi:10.1177/1052562906289663

Van Manen, M. (1997). Researching lived experience: Human science for an action sensitive pedagogy. London, ON, Canada: The Althouse Press, University of Western Ontario. 